\title{
Reflexión sobre la migración transnacional y transcultural en el Estado de México desde la perspectiva de la paz y los conflictos
}

Reflexão sobre a migração transnacional e transcultural no Estado do México a partir da perspectiva da paz e conflitos

Reflection on transnational and transcultural migration in the State of Mexico from the perspective of peace and conflict

\section{Eduardo Andrés Sandoval Forero}

- Doctor en Sociología, Maestro en Estudios Latinoamericanos, y Antropólogo Social.

- Miembro del Sistema Nacional de Investigadores de México nivel II desde 1995.

- Profesor invitado de universidades de: Estados Unidos, América del Sur, España e Italia.

- Fundador y Coordinador Académico de la Maestría y el Doctorado en Educación para la Paz y la Convivencia Escolar en México.

- Investigador-Profesor del CIEAP, Universidad Autónoma del Estado de México

- Premio Manuel Castillo 2009 otorgado por la Universidad de Valencia, España, por la la investigación académica en el ámbito de la Cooperación para el Desarrollo Humano y la paz de los Pueblos en el mundo. Categoría Estudios e Investigación, publicado en el libro coeditado por Vicent Martínez Guzmán y Eduardo Andrés Sandoval Forero (2009), Migraciones, conflictos y cultura de paz, Cátedra Unesco de Filosofía para la Paz, Bancaja, Universitat Jaume I, Castellón, España

- E-mail: forerosandoval@gmail.com 


\section{Resumen}

La complejidad de fenómenos sociales como son la migración, la pobreza, la violencia, el despojo, los conflictos entre otros son parte del repertorio que constituyen las particularidades propias de la sociedad globalizada del siglo XXI, dicha escenario se constituye como un referente de análisis sobre las problemáticas que afecta directamente los grupos subalternos y oprimidos de nuestra época. Por ende, la necesidad de avanzar en esta lógica orientada a la reflexión crítica de fenómenos como son la migración transnacional y transcultural implica un desafío en el ámbito de conceptualizar dicha temática a partir de los estudios de paz y los conflictos en sus respectivos contextos y dinámicas sociopolíticas de Nuestra América. Así pues, la finalidad del siguiente artículo consiste en exponer la relación teórica, conceptual y metodológica que existe entre la migración, la paz, y el conflicto reflejado en el ámbito transnacional y transcultural que presenta la experiencia migratoria de la población del Estado de México. Uno de los aportes más relevantes encontrados en esta investigación consiste en la amplia relación entre la perspectiva crítica de concebir la migración como un fenómeno que articula el conflicto, la violencia y la paz y la emergencia de estudios en este campo de la investigación social.

PALABRAS CLAVES: ESTUDIOS PARA LA PAZ•VIOLENCIA • MIGRACIÓN TRASNACIONAL • MIGRACIÓN TRANSCULTURAL•ESTADO DE MÉXICO.

\section{Abstract}

The complexity of social phenomena such as migration, poverty, violence, dispossession, conflicts, among others, is part of the repertoire that constitute the peculiarities of the globalized society of the 21 st century. This scenario constitutes a benchmark for analysis of the problems that directly affect the subaltern and oppressed groups of our time. Therefore, the need to advance in this logic oriented to the critical reflection of phenomena such as transnational and transcultural migration implies a challenge in the scope of conceptualizing this topic from the studies of peace and conflicts in their respective contexts and sociopolitical dynamics of Our America. Thus, the purpose of the following article is to expose the theoretical, conceptual and methodological relationship that exists between migration, peace and conflict reflected in the transnational and transcultural context presented by the migratory experience of the population of the State of Mexico. One of the most relevant contributions found in this research is the wide relationship between the critical perspective of conceiving migration as a phenomenon that articulates conflict, violence and peace, and the emergence of studies in this field of social research.

KEYWORDS: KEYWORDS: STUDIES FOR PEACE・VIOLENCE •TRANSNATIONAL MIGRATION・TRANSCULTURAL MIGRATION•STATE OF MEXICO.

\section{Resumo}

A complexidade de fenômenos sociais - como migração, pobreza, violência, desapropriação e conflitos, entre outros - é parte do repertório que constitui as particularidades próprias da sociedade globalizada do século XXI. Esse cenário se mostra como um referente de análise sobre as problemáticas que afetam diretamente os grupos em situação de vulnerabilidade e oprimidos de nossa época. Por essa razão, a necessidade de avançar nessa lógica orientada à reflexão crítica de fenômenos como migração transnacional e transcultural implica um desafio no âmbito da conceituação da referida temática a partir dos estudos para a paz e conflitos nos seus respectivos contextos e dinâmicas sociopolíticas de nossa América. Assim, a finalidade deste artigo é expor a relação teórica, conceitual e metodológica que existe entre migração, paz e conflito refletida no âmbito transnacional e transcultural que apresenta a experiência migratória da população do Estado do México. Uma das contribuições mais relevantes encontradas nesta pesquisa é ampla relação entre a perspectiva crítica de conceber a migração como fenômeno que articula o conflito, a violência e a paz e a emergência de estudos nesse campo de pesquisa social. 


\section{INTRODUCCIÓN}

a migración como un campo de investigación en las ciencias sociales ha tomado gran relevancia debido a los cambios estructurales del sistema - mundo globalizado. La crisis civilizatoria que afecta de forma radical los distintos grupos sociales en la esfera política, económica, cultural, social, étnica entre otras, no es ajena a la realidad de los migrantes en donde la construcción de los imaginarios colectivos con respecto a la migración ha sido un debate de larga duración, dado el contenido, la complejidad y la evolución que ha traído consigo este fenómeno de orden global.

Desde la perspectiva de los estudios sociales en torno a la migración se ha podido constatar una serie de avances en materia de la investigación social que ofrecen elementos necesarios para logar analizar la complejidad de esta problemática en sus respectivas particularidades. Así pues, la migración transnacional como una vertiente de estudio responde a un fenómeno de carácter novedoso, dado su contenido en función de caracterizar los desplazamientos internacionales, los flujos de movilización poblacional de un territorio a otro, la dislocación y desestructuración de la "comunidad tradicional", el cambio de paradigma de la ciudadanía y el debilitamiento de la esfera pública de los Estados, son parte de las transformaciones que han sucedido en las últimas décadas en América Latina.

En este sentido, la necesidad de analizar de forma crítica las dimensiones que integran los procesos migratorios en materia territorial, espacial, temporal y societal hace parte del juego estructural por reconocer la problemática en su extensión y profundidad, esto implica tener que mostrar el carácter múltiple de la migración. Asimismo, se convierte en un espacio de reflexión por reconocer, caracterizar y desarrollar los principales elementos culturales de las localidades, comunidades y grupos sociales involucrados en este fenómeno de investigación social.

El panorama actual obliga a reconocer que:

nos encontramos con una globalización capitalista que de manera colateral impulsa la migración transnacional, haciendo que las cantidades de mano de obra sobrante en otras regiones del mundo se utilicé donde el capital la necesita, sin importar los mecanismos de traslado de los migrantes, ni tampoco las violaciones a los derechos humanos que en forma recurrente se realizan con esta población vulnerable y deportable (Sandoval Forero, 2015, p. 12).

Al mismo tiempo, la migración al ser un fenómeno social, político, económico y cultural se encuentra relacionada con la dinámica del conflicto, la paz y las violencias que existen en los procesos de movilización de las sociedades globalizadas, es decir, las múltiples dimensiones que influyen o repercuten en esta problemática mundial se encuentra relacionadas a situaciones como el desplazamiento forzado, refugio, asilo político, exilio, empleo y la falta de oportunidades que afectan directamente al sujeto migrante.

El argumento de relacionar la migración como un fenómeno que responde a un ambiente de intolerancia, conflictos, violencias y situaciones complejas al nivel local, regional, nacional e internacional, tiene como fundamentación la dinámica proveniente del capital, la mercantilización del sujeto, la apertura del mercado en las fronteras y las políticas restrictivas que impulsan la configuración de un imaginario basado en la violación de los derecho humanos, la falta de diálogo y solidaridad con el migrante y la poca capacidad institucional destinada a garantizar la protección de la vida, la familia y las mínimas condiciones para el libre desarrollo como ser humano.

En efecto, tener un acercamiento sobre la compleja realidad que representa la migración, sirve como un antecedente que permite explorar los flujos, movimientos e interacción generada en el campo nacional e internacional debido a las condiciones 
que contribuyen a la configuración de una cultura de la migración que demuestra por una parte la poca capacidad institucional de canalizar las demandas de los grupos sociales más vulnerables de una sociedad permeada por las condiciones de un ambiente globalizado (Bryceson; Vuorela, 2002; Sandoval Forero; García, 2010).

El fenómeno de la migración de población mexicana para Estados Unidos, es un situación de hace más de un siglo de manera permanente con periodos de flujos y reflujos en sus intensidades y con entidades federativas tradicionales de expulsión y con mayores índices de desigualdad social. En particular, la experiencia en el Estado de México, al ser la entidad federativa más poblada del país, se ha constituido en los últimos quince años en un lugar emergente de migración causada principalmente por el deterioro de las condiciones económicas de la mayoría de su población, es decir los altos niveles de corrupción, clientelismo y pobreza - estructural.

De esta manera, la visión de autores como Glick, Basch y Szanton - Blanc sobre el estudio de las comunidades transnacionales en su origen, desarrollo, crisis y finalidad en el mundo - social es de gran vitalidad para realizar una contextualización en el panorama regional. Por ello, la configuración de las comunidades transnacionales y transculturales mexicanas responde a un eje de discusión que hace uso de la etnografía mutilsituada y la sociología virtual dos campos de investigación propicios para reconocer las dinámicas de tipo cultural, económico y político en sus respectivas dimensiones como son: lo local, lo estatal, y lo federal (Sandoval Forero, 2015; Zapata-Barrero, 2004). Igualmente, se parte de reconocer que el flujo migratorio responde a los intercambios fronterizos, interculturales, interétnicos y multidimensionales debido a la naturaleza y propiedades de las poblaciones y territorios con gran movilización migratoria.

Así pues, la finalidad del siguiente artículo consiste en analizar a partir de un enfoque crítico- emergente como lo representa la perspectiva decolonial en el estudio de la migración, la esfera de las comunidades en el plano transnacional y transcultural, y por último, la relación teórico-analítica del panorama de la migración a partir de las particularidades existentes de la población migrante en el Estado de México como sucede en el municipio de Tonatico, llegando al punto de mencionar la emigración al extranjero como un fenómeno que debe ser visto más allá de la dicotomía sociedad - Estado, economía - política y pasar a una lógica crítica de las propiedades que mantiene los inmigrantes con la población de origen en su trayecto, experiencia y reconstrucción histórica de su condición como ciudadano migrante.

\section{ESTUDIOS DE PAZ Y VIOLENCIA EN EL FENÓMENO DE LA MIGRACIÓN CONTEMPORÁNEA}

Los estudios de paz se han convertido en una temática de gran utilidad en la compresión del fenómeno de la migración en sus distintos niveles, así la violencia y el conflicto simbolizan elementos constitutivos de cualquier acción humana al interior de la sociedad, esta perspectiva de reconocer como un hecho social los procesos migratorios implica una forma de abordar teórica, conceptual y analíticamente dicha problemática a través de una experiencia investigativa que responda a los debates metodológicos y la misma naturaleza de una sociedad globalizada.

La concepción teórica proveniente del conflicto, la memoria, la paz y la violencia sirve como elementos para el análisis profundo de las problemáticas internacionales que influyen radicalmente en cualquier tipo de migración (legal o ilegal), a su vez, es un factor determinante que permite realizar un abordaje más amplio sobre la experiencia, la narrativa, la práctica y la subjetividad producto de la praxis del sujeto migrante en su trayecto de vida.

Por ende, la migración transnacional y transcultural se encuentra asociada a un proceso en donde 
las constelaciones migratorias no son un fenómeno nuevo ni aislado y su estudio requiere de un enfoque multidisciplinario que aborde desde sus causas el tránsito, la llegada, las distintas consecuencias, el retorno, las regiones expulsoras de población, los países receptores, la demografía de las migraciones, las políticas migratorias, los derechos de los migrantes y la feminización creciente de la movilidad humana entre otras (Sandoval Forero, 2012, p. 234).

Siendo un aspectos de suma importancia en la perspectiva de los estudios de paz en el análisis de la migración, puesto que se enfoca en construir investigación por medio de la visión analítica, compleja y estructural de ver a los migrantes como actores vulnerables en el sistema mundo. En este sentido, la matriz de referencia teórica y metodológica sobre el fenómeno migratorio responde a la incursión de investigaciones de naturaleza explicativa o reflexiva que permite articular la dinámica micro o macro producto de la migración en un contexto global.

El paradigma del estudio de paz encargado de comprender la multicausalidad que constituye el fenómeno de la migración: causas, destino, traslado, consecuencias, retorno e impactos entre otros, plantea la importancia de construir investigaciones teórico - conceptuales por medio de un diseño metodológico que tenga la capacidad de reconocer que cualquier tipo de migración está vinculada a un ejercicio de violencia estructural dado que existen gobiernos, Estados y sociedades proclives a la expulsión de población en distintas circunstancias.

La violencia estructural se constituye como factor que "está edificada dentro de la estructura y se manifiesta como un poder desigual y, consiguientemente, como oportunidades de vida distintas" (Galtung, 1969, p. 171 citado por Sandoval Forero, 2009, p. 23). Este tipo de violencia contribuye al fortalecimiento de las causas endógenas y exógenas propias del fenómeno migratorio.

A su vez, el proceso de migración producto de la desigualdad estructural, la falta de oportunidades, las prácticas políticas indebidas y las lógicas del sistema mundo inmerso en la mercantilización de la vida y la acumulación del capital son características que hacen que el sujeto migrante tenga que recurrir a transitar de una país, sociedad, gobierno y estructura sociocultural distinta a la de su origen.

La violencia generadora de un imaginario de explotación, pobreza y un escenario de abandono estatal sobre la población migrante se articula con los bajos índices y debilidad institucional que presentan los gobiernos en sus respectivos regímenes democráticos, lo que significa un Estado promotor de violación a los derechos humanos, derechos políticos y una sociedad con precarios niveles de desarrollo social, político, económico, cultural y educativo.

Otro aspecto que influye en la construcción de una cultura migratoria consiste en las prácticas sociales que se han configurado históricamente al interior de sus familias, ya que por diversas causas han recurrido a la actividad de migrar en búsqueda de mejores oportunidades y las futuras generaciones lo concibe como un imaginario que debe reproducirse argumentando dichas razones y otras que son válidas para asumir la travesía de la migración.

Por otro lado, los actores que generan, produce y contribuyen a la construcción de conflictos violentos al interior de la sociedad hacen parte de la dinámica sociopolítica que se imponen sobre los grupos subalternos y oprimidos de cualquier país, siendo un elemento estructural que repercute en las prácticas de actores armados precursores de la violencia física, directa y radical contra los distintos sectores de la sociedad que se ven obligados/forzados a sumarse a las filas del desplazamiento interno, el refugio humanitario y el abandono de proyectos de vida como sujeto político en cada uno de sus territorio.

La complejidad que representa la migración internacional responde a una persecución política, ideológica y humana que realiza los Estados contra cualquier actor disidente sobre la forma de gobernar en el país, esta problemática fortalece la cultura de la violencia directa, el uso indiscriminado de la fuerza legal, la masificaciones de grupos policiales y las prácticas 
de expulsión, despojo y estigmatización contra cualquier sujeto político que piense, actúe y manifieste una postura contrario a las estructuras gubernamentales.

Las dinámicas de un mundo globalizado donde el sujeto se encuentra inmerso en una serie de cambios coyunturales 0 estructurales, implica reconocer el fenómeno migratorio como una muestra del desplazamiento de hombres y mujeres, que dejan su lugar de origen con el fin de instalarse en otro país sin tener conocimiento propio sobre el país receptor. Esta situación ha sido considerada como un fenómeno social de larga duración donde las consecuencias recaen en lo cultural, económico y político que tiene un Estado, al inducir que su población abandone su patria en búsqueda de un sueño o un proyecto que vio casi o imposible de materializar en su nación.

Por ende,

estas migraciones en tiempos de la globalización económica presentan múltiples relaciones y complejidades que en muchos casos configuran interrelaciones sociales y culturales de carácter colaborativo y pacífico, mientras que en otras circunstancias, como en el caso de la migración indocumentada, pueden generar relaciones interculturales desiguales, marcadas por el pleno desconocimiento y desprecio hacia la cultura de los inmigrantes, afectando negativamente la calidad de vida de las personas (Sandoval Forero, 2007, p. 10).

La lógica de la migración internacional tiene que ver con el cruce de fronteras por diversos motivos: las oportunidades laborales, la crisis familiar, los problemas de seguridad, la precariedad económica y la falta de garantía por ser reconocido como sujeto de derecho, es decir, ciudadano con las mínimas garantías dentro de una democracia. Esta serie de déficits son parte del repertorio de motivos que conlleva a un proceso de movilización de diferentes grupos a territorios donde se tiene un tipo ideal de conseguir una mejor "calidad de vida". A esta particularidad, se suma el constate movimiento de la Sociedad de la Información por medio de las redes sociales, los medios alternativos y los espacios virtuales que simbolizan un circuito migratorio en el tema de la interacción, la comunicación y la generación de espacios para seguir manteniendo los lazos de solidaridad y afectividad en medio de la distancia con las familias que habitan en su lugar de origen.

Por el contrario, a esta realidad se le suma el discurso y la praxis que hacen uso el Estado para seguir generando exclusión frente a los migrantes. Una muestra lo encontramos cuando:

\footnotetext{
los gobiernos de los países desarrollados han elaborado y aplicado un sin número de leyes antimigratorias y restrictivas de diversa naturaleza, en especial contra la fuerza de trabajo de calificación baja; pues en ciertos casos son flexibles con algunos trabajadores migrantes calificados o con experiencia en tecnología avanzada. Al mismo tiempo, una de las expresiones de las políticas antimigratorias es la identificación de los migrantes como elementos "ilegales", "perturbadores" y "subversivos" del orden estructural de los países receptores. Se les niegan derechos elementales como seres humanos y derechos básicos como trabajadores; se les persigue, encarcela, deporta y en no pocos casos desaparecen o son eliminados físicamente (Sandoval Forero, 2007, p. 14).
}

Así pues, la concepción desarrollada sobre los imaginarios colectivos que genera la dinámica de emigración en los territorios, responde a una serie de consideraciones vinculadas con la complejidad del vínculo socio- político entre los Estados, las sociedades y los cambios culturales en cada país. Permitiendo la emergencia de una realidad multicultural donde lo transnacional (rompe fronteras) y lo transcultural (más allá de una cultura) se encuentran en medio de un choque entre dos imaginarios diferentes pero no excluyentes de un fenómeno global como lo representa la migración entre el sujeto colonizador y colonizado en una relación en constante disputa política. 
El discurso analítico sobre la comunidad transnacional está asociado a un conjunto de prácticas, discursos y acciones en un escenario multipolar mediado por la lógica del sistema - mundo, dado que se encuentra sometido a los intereses del capital, la mercantilización del ser y la banalización de la política frente a la dignidad de lo humano en comunidad. (Wallerstein, 2005). Este conjunto de procesos transnacionales también influyen: las relaciones entre las culturas de los inmigrantes y las de la sociedad receptora, genera conflictos diversos que en muchos casos son atendidos mediante la coerción, la confrontación, la represión y las violencias. La lista de las violaciones y atropellos a los derechos humanos de los migrantes no documentados o irregulares, es tan grande como los mismos flujos internacionales, y van desde la cacería humana, el desprecio a las personas, maltratos de la autoridad, tortura física y psicológica, desaparición, tratos crueles y degradantes, detención y hasta la violación al derecho a la vida.

Esta situación se presenta en condiciones de confrontación cultural que pueden llegar a la presencia de violencia directa, violencia cultural, violencia psicológica, violencia simbólica y violencia emanada de la xenofobia. En otras circunstancias, las relaciones de la diversidad de las culturas en contextos migratorios son de convivencia pacífica, no violenta, de respeto, reconocimiento mutuo y de armonía.

En este sentido, las comunidades y las familias caracterizadas por estar asociadas a un contexto transnacional responden a un entramando de relaciones socio- políticas en el marco de un escenario internacional fragmentado y dividido por la crisis del capitalismo moderno - colonial, es decir, participan y conviven en medio de las circunstancias propias de los grupos subalternos y los movimientos de la globalización desde abajo, aquí las comunidades están constituidas a través de redes sociales de familias, acciones comunicativas, interacción comunitaria haciendo uso del internet y una serie de cambios interculturales donde la condición de ser migrante toma mayor sentido en el diario vivir en su espacio local, nacional e internacional (Díaz, 2015). Es una globalización migratoria desde abajo en sentido de convivencia pacífica.

Una evidencia concreta la encontramos con los:

flujos migratorios que también se inscriben dentro del contexto de los grandes avances científicos y tecnológicos, particularmente en el de las Nuevas Tecnologías de Información y Comunicación (NTIC) que de manera importante y sin precedentes para la humanidad, ha inducido la globalización de los mercados y las economías. Para los migrantes también las NTIC han sido importantísimas para la comunicación y resolución noviolenta de problemas y conflictos con sus familiares, amigos, vecinos y comunidad (Sandoval Forero, 2007, p. 17).

La identidad que se construye a lo largo del trayecto en su antes, el después y lo acontecido en la cotidianidad de los migrantes, puede ser asimilada como el reflejo de un proceso cultural donde la práctica social (apropiación del presente) y la visión utópica (apropiación del futuro) son congruentes con la necesidad - real del sujeto a través de su conciencia frente a su realidad - empírica. Un aspecto que posibilita la construcción de un:

imaginario colectivo que hace referencia a la construcción simbólica que carga de sentido el pensar y el actuar de las personas con relación al acontecer migratorio. Tiene que ver con parte de la realidad social de los inmigrantes, de los retornados y de la comunidad de origen. Pero también tiene que ver con las formas subjetivas del pensar, con las percepciones, representaciones y fantasías sobre la dinámica social de una comunidad que ha hecho suya la cultura de la migración (Sandoval Forero, 2013, p. 3).

Por otra parte, la perspectiva transcultural en el marco de la experiencia del sujeto - migrante corresponde a ese diálogo, interacción y comunicación con otros sujetos, contextos, espacios y temporalidad ajena a su realidad de origen, son elementos causantes de una hibridación cultura que contribuyen a un tipo de identidad. Un aspecto que marca la ruta cotidiana por convivir y relacionarse con el mundo - social, del cual no es nativo, pero está en el deber de encontrar su necesidad real sin desconocer las circunstancias socio - políticas que lo acontecen como migrante. 
El sentido de la movilización que trae consigo el migrante desde su lugar de origen y la necesidad de apropiarse paulatinamente del nuevo espacio, lo lleva a enfrentarse constantemente a prácticas, discursos, mensaje, acciones e imaginarios desconocidos en su campo cultural pero que son recibidos, asimilados y asumidos de forma prolongada a lo largo de su estancia o residencia del país receptor. De este modo, el giro - radical que experimenta el migrante es un elemento de suma importancia frente a la cuestión de lo transcultural, dado que las practicas del sujeto ubicadas más allá de las fronteras son un insumo en la lógica de concebir otras formas de realidad socio - política donde la incursión, participación (activa - pasiva) y la adaptación del migrante y las familias al nuevo contexto repercute en la transformación de la cultura establecida producto de la experiencia del sujeto.

Un elemento que se relaciona de forma analítica, puesto que:

los migrantes son quizás los actores sociales que mejor entienden la complejidad y efervescencia del mundo actual, al tener que sortear la reconstrucción de su espacio, su tiempo, y su hábitat en territorios que les plantean situaciones inéditas en su actuar social del pasado y del presente. Nuestro manejo del tiempo, el espacio y el hábitat, es un fenómeno cultural que interiorizamos progresivamente en la construcción del día a día, del vivir cotidiano (Mora; Sandoval Forero, 2010, p. 70).

La interacción resultado de la actividad de la migración es una muestra de la apropiación de otros espacios. Tal como sucede con el uso de las Nuevas Tecnologías de Información y Comunicación (NTIC), al interior de las familias fragmentadas por la ausencia de alguno de sus integrantes o el dejar atrás su antigua vida e incursionar en nuevas tierras expuestas a cualquier circunstancia del momento. La cuestión reside en la generación del ciberespacio en este intercambio familiar en donde la comunidad de migrantes residentes en otro país (México - Estados Unidos). Este entramado cultural de bienes, experiencias, miedos, retos, esperanzas, fracasos y oportunidades son constitutivas del fenómeno transcultural por reconocer, apropiarse y asumir otra percepción sobre la cultural, la identidad y el pasado - vivo, en el que constantemente se enfrentan los migrantes de uno y otro lado de la frontera.

El intercambio de lógicas discursas forman parte de la características del migrante en su relación con los medios de comunicación y la virtualidad, debido a la construcción de sus propios elementos culturales a partir de la identidad, la cultura y la resistencia por mantener, promover y defender sus habitus cotidianos (alimentación, expresiones, ideas, sentimientos, motivos entre otros). Igualmente, "la comunicación e información virtual on line está integrada por usuarios que catalizan la usabilidad de las redes en las NTIC. Entendemos por usuarios a "los ciudadanos y organizaciones que participan de la sociedad de la información a través de la generación, uso y difusión de la información" (Valenti, 2002, p. 18 citado por Mora; Sandoval Forero, 2010, p. 65).

Al mismo tiempo, el constante flujo e intercambio de migrantes, familias y actores sociales sobre la lucha y/o disputa por rebasar los límites espaciales, territoriales y geográficos que conciernen las márgenes de fronteras establecidas por los Estados, son parte del carácter transnacional de los movimientos migratorios en la actualidad. Se convierten en la razón de ser por analizar las transformaciones culturales de la sociedad receptora de este tipo de población vulnerable mostrando los elementos necesarios para reconocer la dinámica del circuito migratorio que va desde la llegada (travesía) hasta el establecerse (material) en un espacio para continuar su desarrollo personal.

La visión de lo transnacional y lo transcultural en los estudio de la migración tiene como base el reconocimiento del sujeto - migrante en su condición como un actor social, aunque haya abandonado su lugar de origen no implica que pierda sus derechos humanos. Por el contrario, podría ser asimilado como un fenómeno socio-económico donde prácticas como el envío de remesas, la comunicación con la familia, la participación de actividades remuneradas tanto documentado como 
indocumentado, la presencia activa del inmigrante en los asuntos locales del país receptor hacen parte del conjunto de elementos que contribuye a los procesos de desarrollo pacífico en ambas naciones.

Por ende,

\begin{abstract}
"se trata de una imagen que en el concepto de comunidad presupone el entrecruzamiento de varios espacios y significados y deriva de lo que en sí misma es la migración" (Moctezuma, 2008: 55), en donde la comunidad transnacional que se recrea en el circuito migrante es imaginada, y de hecho, todas las comunidades lo son, ya que la pertenencia a una misma comunidad cultural lleva a concebir a los otros con los estándares de un lenguaje, cultura y sistemas simbólicos dados (Mora; Sandoval Forero, 2010, p. 71-72).
\end{abstract}

La dimensión micro y macro de la migración en el reconocimiento de las familias representa un espacio de fragmentación de valores, creencias, afectos y sentimientos dada la complejidad de lo que implica la distancia y el vivir en otro contexto. Sin embargo, en ciertos casos la conexión mejora, se fortalecen los sentimientos de pertinencia y existe una mayor apropiación de dinámicas/ estrategias para buscar fortalecer la familia en su ámbito transcultural y transnacional (Bryceson; Vuorela, 2002).

El planteamiento teórico de reconocer lo transcultural y transnacional, puede ser asimilado en dos momentos. El primero tiene que ver con la ruptura de frontera y el segundo corresponde con la subjetividad del sujeto dentro de su experiencia migratoria. Una forma de asumir esta situación, consiste en la capacidad de reflexionar sobre la importancia de las experiencias locales, nacionales e internacionales, puesto que se encuentra interconectas por las relaciones socio - económicas del sistema - mundo en un ambiente globalizado y despolitizado por el capitalismo.

De esta forma, dichas categorías se articulan bajo la visión de la multiculturalidad e inmigración en medio de la construcción de un tipo ideal sobre la ciudadanía y la democracia en los distintos países del mundo. El debate histórico de origen colonial por imponer una discusión donde el migrante no puede ser reconocido como un ciudadano en la esfera pública. Tal como lo considera Zapata-Barrero (2004, p. 34) al señalar que la categoría de "'ciudadanía' ha sido históricamente una noción excluyente. Su semántica ha connotado constantemente un privilegio y un límite social, ético, político y económico frente a las demás personas no incluidas dentro de su alcance semántico".

Por ello,

todas estas realidades de menosprecio, discriminación y exclusión hacen del inmigrante un ciudadano de segunda categoría que afecta su condición de sujeto de derecho con menosprecio cultural, produciendo una serie de barreras o limitaciones al ejercicio de sus derechos fundamentales, ya sea amparada por normas contrarias a los derechos humanos e incluso por el sector privado que actúa aprovechando esta situación de manera consciente, u obligado por la legislación de aquellos países que sancionan a los empleadores de inmigrantes indocumentados, donde el Estado pretende detener los movimientos migratorios valiéndose del uso inadecuado del derecho y de la manipulación de su sociedad que percibe en lo ajeno una amenaza y no una oportunidad de desarrollo (Sandoval Forero, 2015, p. 24).

Países como Estados Unidos de Norteamérica han fincado parte de su gran potencial de desarrollo en el uso de la fuerza de trabajo de millones de inmigrantes indocumentados.

La perspectiva liberal de la ciudadanía y su relación con la democracia ha tomado como bandera la libertad económica y la capacidad de asumir, participar y debatir sobre los asuntos públicos de forma deliberativa. Sin embargo, la realidad política que vive la comunidad de migrantes se ve expuesta a una serie de discursos como son la identidad nacional, la defensa del territorio, la nacionalidad, los derechos especiales y la patria, son parte del cúmulo de conflictos que integran 
las problemáticas de los migrantes indocumentados en esta época contemporánea y son defendidos por los grupos ortodoxos del país receptor.

La diatriba teórica - conceptual de la multiculturalidad en el estudio de la migración, radica en su ethos liberal en función del individualismo y la apuesta por construir una categoría universal sobre la ciudadanía, en esta apuesta, se ha excluido históricamente a los grupos sociales oprimidos (mujeres, negros, indígenas, campesinos, migrantes), debido a que no formaron parte de esta distinción y pasaron a ser considerados como un sector ajeno a ser ciudadanos. En este sentido, el discurso de la multiculturalidad con el paso del tiempo asumió una distinción y se enfocó en reconocer un posible escenario plural donde estos grupos pasaran hacer reconocidos pero a partir de las categorías y las lógicas del sistema mundo - capitalista.

Por su parte, los cambios provenientes de un mundo globalizado y multicultural constituyen las sociedades complejas en materia económica, política, social, demográfica, espacial y territorial, debido a la dimensionalidad de los procesos internos/ externos que aparece en el fenómeno migratorio. Un aspecto que involucra identidades subalternas, redes familiares virtuales, intercambios socio- económicos, prácticas culturales entre los sujetos y la exploración de espacios de organización entre los migrantes, constituyen una forma de reconocer los elementos de gran importancia en el estudio de la migración transcultural y transnacional.

En el plano del multiculturalismo como un modelo de caracterización del ciudadano en un espacio globalizado en el ámbito económico, político, cultural y social, contribuye a que los migrantes pasen a ser asimilados como un actor que vive en medio de la multiplicidad de crisis (capital, familiar, pensamiento, acción, sentimiento), una época donde la tecnología y el acceso a otros medios de comunicación alternativo repercute en el significado de la experiencia y el ethos del migrante como sujeto - político en un país desconocido para el mismo. Desconocimiento social, cultural y lingüístico que en muchos casos se convierten en verdadero conflicto y que suma a los conflictos de la situación indocumentada de millones de migrantes.

Ahora bien, el tema del multiculturalismo y su relación con la migración responde al reconocimiento del escenario complejo y lleno de contradicciones entre el sujeto y el capital, la política y la economía, la soberanía nacional o la internacionalización, el patriotismo o nacionalismo entre otros, es decir, discurso enclaves del proyecto moderno - colonial que responde a una lógica de corte ideológico que se ha incrustado en las políticas del Estado, en donde han puesto en desigualdad al sujeto - migrante y asumiendo un estado de negatividad y exclusión por parte de los sectores gubernamentales.

La tendencia sobre el multiculturalismo no solo tiene cabida al interior de las políticas de la ciudadanía y la esfera pública. Por el contrario, intenta abarcar o conocer diversas culturas pero con el paso del tiempo pasa a ser un instrumento que es usado por parte de los estados para construir procesos políticos en función de la estratificación social y la desigualdad entre actores que conforman un régimen político. Una gran problemática dado el contenido y la esencia de la pluralidad en el marco de los derechos humanos como herramientas que pueden ser de uso para los migrantes, al momento de ser víctimas de la fuerza estatal en su trayecto hacia el país receptor.

El problema de poner en relación el multiculturalismo y la migración como dos estadios de pensamiento, tiene que ver con la contextualización de los fenómenos producto del proyecto postergado y colonial de la modernidad. Una estructura que da prevalencia a la racionalidad instrumental, la neoliberalización de la economía y la violencia - sistémica contra la dignidad humana de estos actores que son vistos y tratados como ciudadanos de segunda categoría. Lo que conlleva a la implementación de un proyecto que responde a los intereses hegemónicos del gran capital y la barbarie de la razón del Estado que pasa por encima del sujeto y está en alianza con la exclusión, el racismo y la xenofobia contra los migrantes siendo insumos del régimen del colonialismo impuesto en las latitudes Latinoamericanas. 
Las asimetrías generadas a lo largo del recorrido que realizan los migrantes nos permite conocer con mayor precisión el plano social y cultural, debido a que entra en juego la subjetividad del migrante frente a la experiencia de conocer un contexto distinto al de su origen. Lo que posibilita el fortalecimiento de prácticas de discriminación, negación y exclusión - multidimensional (política, económica, simbólica y social) de aquellos sujetos que no son nativos u originarios del territorio al que se llega.

Del mismo modo, la perdida de la soberanía, la estigmatización y la invisibilización del migrante son elementos que facilitan reconocer la pérdida gradual de la condición de ciudadano en un escenario transnacional y transcultural. Una situación que motiva la generación de análisis más riguroso sobre la relación, el proceso y la construcción del sujeto, el espacio y la realidad constituida por medio de la identidad cultural del trayecto migratorio. Por ello, las:

\begin{abstract}
construcciones simbólicas generadas en la población de origen, son igualmente diversas y tienen que ver con los diferentes tipos de migrantes: los que emigran y no regresan, los que van y vienen, y los que se regresan definitivamente para no volver a salir de sus poblaciones de origen. Esas construcciones simbólicas también tienen su base en los vínculos establecidos con los inmigrantes en Estados Unidos, en esa transterritorialidad de relaciones que se concretan por medio de la familiaridad y las redes migratorias de paisanos y amigos, todo lo cual incide en esa construcción histórica de la cultura migratoria (Sandoval Forero, 2013, p. 9-10).
\end{abstract}

Precisamente parte de estas situaciones contribuyen a la generación de conflictos interculturales, los cuales son cada vez más relevantes y agudizados por las políticas públicas de los Estado enfocadas a rechazar y debilitar el status ciudadano del migrante en consonancia con los derechos humanos y los tratados internacionales que dan legalidad a la calidad de los migrantes y el movimiento transcultural y transnacional que se presencia en la sociedad contemporánea de nuestros tiempos.

La lógica de estudiar la migración desde lo transcultural y lo transnacional también implica la aparición de experiencias en el imaginario social, simbólico y político del sujeto. En donde aparece el sentido que Castoriadis (1993) argumenta como el imaginario en la sociedad, aquí las redes simbólicas son un instrumento de representación y significados a partir de la experiencia e interacción del sujeto en el ámbito de lo social. Asimismo, las representaciones sociales están inmersas en el plano de la conciencia del individuo frente a la compatibilidad de su relaciones societales.

El marco de representación que existe en el imaginario social puede ser colectivo o individual, sirve para reconocer los elementos que constituyen el fenómeno transcultural y transnacional que viven las familias migrantes y como este facilita la compresión de las relaciones indisoluble, la unidad y la precariedad que enfrenta en su travesía el sujeto - migrante siendo una característica para comprender el hombre (ser genérico) en su vida social (Castoriadis, 1993; Sandoval Forero, 2007).

El enfoque critico de reconocer las principales características que conforman lo transcultural y transnacional en el estudio de la migración, responde a una serie de particularidades producto de cada una de las experiencias de las familias, individuos 0 actores vinculados con el proceso migratorio. Así pues, la realidad socio - histórica, el contexto del individuo y las condiciones reales de donde proviene son insumos que influyen de manera categórica en las formas simbólicas, espaciales, culturales y cognitivas donde la producción, reproducción y redimensión de la realidad, el ambiente social y la cultura son la base del estilo de vida del migrante en el proceso de adaptación de su nueva vida en el extranjero, la que con el transcurrir del tiempo le otorga acoplamientos culturales y mejores condiciones de vivencia pacífica.

Por ende, la configuración de la comunidad transnacional y transcultural esta mediada por los cambios de tipo cultural y políticos de donde son provenientes los migrantes. Una condición que sin lugar a dudas repercute en los dos lados de la frontera prácticamente por medio de las actividades cotidianas, las relaciones sociales y la interacción del migrante con las comunidades residentes del país de llegada. La necesidad de reconocer esta serie de prácticas que hacen parte de 
un conjunto de piezas fundamentales que permiten tener una mirada profunda en materia de intercambios económicos, culturales, simbólicos y afectivos entre las familias migrantes.

\section{LAS VIOLENCIAS ESTRUCTURALES Y LA CULTURA DE PAZ EN LA MIGRACIÓN}

Las violencias estructurales son un conjunto de fenómenos que generan un ambiente de incertidumbre y crisis al interior de la sociedad, esta situación tiene que ver con las prácticas, discursos y acciones que el Estado, los grupos, sectores y actores políticos, económicos y culturales construyen en los distintos espacios de la ciudadanía para y en lo público.

En efecto, la violencia directa producida y facultada por el Estado contiene en su praxis un contenido cultural, simbólico y analítico que influye en el imaginario colectivo de los grupos sociales de manera positiva o negativa, por ende, este conjunto de prácticas conflictivas son el resultado de un discurso que pretenden justificar / legitimar cualquier forma de violencia estructural contra los sectores subalternos de la comunidad política (Díaz, 2015).

El retorno de los migrantes representa una práctica real que pone en juego el antes y el presente resultado de la experiencia acontecida en el país receptor, un aspecto que contiene vivencias de violación, robo, decomisos, encarcelamientos, despojos, xenofobia, racismo y negación de su identidad o dignidad humana en los respectivas naciones. Parte de este fenómeno estructural combina cualquier forma de violencia cultural, física, política institucional o directa sobre la población migrante debido a su incapacidad de exigir la legalidad/aplicabilidad de los derechos humanos y políticos en un país en donde no tiene la condición legal de ser ciudadanos ante las instituciones de dicha nación.

La incertidumbre humana que vive el sujeto migrante lo deja en la esfera pública como un actor vulnerable debido a las particularidades que significa el proceso de migración, por un lado, el no tener las mínimas condiciones para subsanar necesidades como son la alimentación, la educación, la salud, el vestuario, la vivienda y sin dejar a un lado el vacío de larga data por tener calor humano, solidaria y amor debido a la falta de sus familiares en dichas situaciones (Sandoval Forero, 1994).

Por otra parte, encontramos un estado de paz imperfecta (negativa o positiva) que se origina producto de los conflictos de intereses entre los gobiernos por hacer peso al masivo exilio y recepción de migrantes en sus países, la falta de solidaria cultural por reconocer la necesidad que vive esta población y la precariedad presente en la ciudadana que conlleva a situaciones de desplazamiento, conflictos y prácticas migratorias son parte del sin fin de interrogantes existentes sobre la migración transnacional y transcultural.

La noción del sentido y los sentimientos dentro de la democracia hacen parte del desafío por comprender las características, elementos, circunstancias que constituyen la migración en un escenario de complejidad, parte de esta discusión ha sido teorizada por Honneth (1997) cuando reconoce que la lucha del otro es producto del esfuerzo por ganarse un espacios y salir de su condición de inmigración a partir de su propia valoración individual y después de la aceptación social, cultural y comunitaria en las respectivas dinámicas de la sociedad civil.

Por tanto, el reconocimiento del sujeto migrante se convierte en un referente intersubjetivo debido a su capacidad de constituir relaciones pacíficas, diálogo entre culturas y procesos de integración en búsqueda de una aceptación y respeto entre ambas partes. La cultura de paz en el estudio de la migración representa un campo de análisis sobre las particularidades producto de las relaciones sociales, la diversidad cultural y la dinámica comunitaria por reconocer al inmigrante como un sujeto valido en la esfera pública, el cual posee una experiencia, un conocimiento, un saber, una cultura y un lenguaje propio que le permite comprender su contexto entre su origen y llegada a la sociedad receptora. 
La voluntad política del sujeto migrante también se articula con el diálogo intercultural y el aporte a diversificar los ámbitos comunitaria de un contexto político, económico e identitario que logre dejar en claro la necesidad de reconocer la sociedad receptora e intentar promover un ambiente de integración mutua, reconocimiento y respeto de la otredad sin tener en cuenta raza, sexo, género, nacionalidad y situación económica entre otras.

Los estudios de paz tiene un campo de gran importancia por seguir profundizando la relación del fenómeno de la migración y su relación con las violencias en los respectivos contextos, naciones o gobiernos, siendo un reflejo de la vitalidad que tiene consigo este tipo de reflexiones que pretenden articular nociones como imaginarios, democracias, subjetividad, inmigrante, cultura de paz, violencia y justicia global sólo por mencionar algunas características que configuran esta problemática transcultural y transnacional en una sociedad globalizada.

Por tal razón, se puede reconocer que:

la contribución de los estudios para la paz obliga a realizar investigaciones relacionadas con la migración y los conflictos, la justicia global y la paz multicultural. Los conflictos inician al salir del país de origen, al transitar por otros, al llegar al de destino. En el país receptor se presentan serios conflictos generados por los inmigrantes hacia la población nativa; también de la población nativa hacia los inmigrantes. En no pocos casos el conflicto se presenta con violencias, y los estudiosos de la paz son los llamados a discernir teórica, analítica y metodológicamente las dimensiones de estos problemas (Sandoval Forero, 2009, p. 26).

El proceso de una cultura migratoria representa una serie de elementos determinantes sobre la vida y contexto del sujeto, puesto que a partir de esta realidad se generan bases sociales no sólo dedicadas a la cuestión económica sino al desplazamiento que trae consigo una narrativa, una historia y un discurso proveniente de su experiencia en tránsito donde toman fuerza las prácticas culturales asociadas a las experiencias de vida en cuanto se interrelacionan con los patrones de transmisión, recepción y producción de tejidos migratorios en lo comunitario, sumado a esto, el uso de las NTIC en el siglo XXI ha transformado las formas de comunicación tradicionales a distintos mecanismos de interacción espacial y temporal del migrante y su espacio familiar.

Por esta razón, los fenómenos de la crisis civilizatoria son cada vez más agudos (discriminación, xenofobia, racismo, sexismo, banalismo) hacen parte de las dinámicas estructurales de larga duración que cargan consigo la historia de los pueblos en Latinoamérica. El ambiente de crisis económicas, los problemas de seguridad y los asuntos propios de la fetichización del poder (corrupción, clientelismo, violencia política) tiene su raíz en el reconocimiento de la magnitud de los problemas cotidianos en la región.

La muestra de una realidad paradigmática en donde los fenómenos estructurales son cada vez más profundos en cada territorio, nos invita a construir reflexiones desde adentro y a partir de la subjetividad del migrante para así conocer las necesidades reales que motivan e impulsan a los movimientos migratorios a gran escala en un contexto de globalización.

La lógica del capital y la economía de libre mercado en Latinoamérica se impusieron como política del Estado por medio del proceso de neoliberalización, aquí los grandes niveles de desigualdades sociales aumentaron en los distintos sectores de la sociedad. La mercantilización de la vida, la naturaleza y la implementación de políticas funcionales a los intereses de la económica (neoliberal) y los grupos hegemónicos del Estado son factores que hacen parte del quehacer de los migrantes desde la salida hasta la llega a otro país (Díaz, 2016).

El fenómeno de migración masiva de distintos grupos sociales (cualificados o no cualificados) es un factor que incide en el reconocimiento del tipo de población que integra el movimiento migratorio de la región, debido a que está ubicada en el marco de una serie de prácticas de exclusión, discriminación e invisibilización, una muestra la hayamos en la migración 
indocumentada que sucede a través del territorio mexicano, lo que se convierte en una problemática - estructural frente al análisis de la dinámica política, cultural, económica y social presente en los sectores migrantes.

De la misma manera,

en la historia de los movimientos migratorios se registran conflictos de los nuevos trabajadores, nuevos refugiados y nuevos pobladores con los gobiernos de los países receptores, autoridades o población civil. Esos conflictos pueden ser de orden jurídico, étnico, social, de clase, político, religioso, racial, cultural o laboral. Los inmigrantes indocumentados, ya sea que se encuentren en países del norte o del mismo sur, se enfrentan con diversos problemas y conflictos que tienen que ver con la dimensión jurídicopolítica, con la violación de sus derechos humanos, con el irrespeto a los derechos de los trabajadores, con el menosprecio a los derechos de los migrantes y sus familiares, con la violación de sus derechos políticos, y con la no aceptación y reconocimiento de sus culturas (Sandoval Forero, 2015, p. 29).

\section{LA MIGRACIÓN EN PERSPECTIVA DECOLONIAL}

La naturaleza colonial que vive, siente y experimenta el movimiento migratorio es la muestra más conducente de reconocer la relación del Estado (instituciones) frente a los grupos excluidos (migrantes) en un marco de procesos coloniales debido al carácter de subordinar y no - reconocer los migrantes como actores que están inmersos en las dinámicas de desigualdades siendo ciudadano de otro país. Igualmente, se concibe como una experiencia donde las personas migrantes, documentales son un actor inmerso en un fenómeno de orden global como lo es la migración (Díaz, 2015).

La necesidad de reconocer la lógica colonial del Estado a través del uso de la fuerza y el monopolio de las armas enmarcadas en un escenario de hostilidad son parte de las historias que los migrantes deben enfrentar. Por un lado, logramos observar como la salida de su lugar de origen les obliga a cargan con una historia viva de segregación, racismo y pobreza para seguir el trayecto donde deben padecer de la violencia estatal en función de un discurso de defensa de las fronteras y la soberanía en el territorio nacional (Galtung, 2003). Llegando al punto donde "la colonialidad se considerará, entonces, en términos de construcción hegemónica de una serie de Caminos/justificaciones en torno al problema de la 'inmigración indocumentada', que trataré de representar mediante esas "cartografías del poder postcolonial" (Díaz, 2015, p. 94).

Una paradoja de esta época donde la globalización ha generado una ruptura con la soberanía, la defensa territorial y el discurso nacionalista que se enfrasca en la patria hasta las fronteras nacionales. En un contexto geopolítico donde la humanidad ha debido salir de su lugar de origen por causas externas a su condición social e individual, una característica que repercute en la necesidad de superar las barreras espaciales de un sistema mundo - colonial y moderno.

Tal como lo señala Grosfoguel (2007) y Sandoval Forero (2016), al reconocer que el racismo epistémico y la exclusión del ser dentro de la lógica colonial del sistema - mundo y la política de Estado frente a los sectores oprimidos, es una de las características con las que se originó y ha fortalecido la colonialidad del poder en el ser, estar y hacer de las estructuras rígidas del capitalismo. En la actualidad, las personas migrantes son víctimas y ha sido re-victimizados por ciertas organizaciones que los han visto como objetos de intereses en el mercado trasnacional una lógica contraria a la razón de ser de la liberación y la justicia social que demanda este movimiento en el marco de una sociedad trasnacional y transcultural pacíficas.

El giro decolonial ha sido un fenómeno epistémico de emergencia en el campo académico, político, cultural, estético, histórico que puso en jaque el velo del eurocentrismo con respecto a las formas de concebir, hacer, percibir y legitimar las ciencias sociales en América Latina. Asimismo, se caracterizó por ser un movimiento con un tipo de insurrección epistemológica 
enfocada en relacionar el saber científico y popular sin generar mecanismos, distinciones o perspectivas que desconozcan los saberes locales producidos por medio de la experiencia de comunidades (indígenas, negras), grupos sociales como mujeres, obreros, campesinos, artesanos sin dejar a un lado la historia viva de los migrantes los cuales cargan con el saber del tránsito territorial (Castro-Gómez; Grosfoguel, 2007).

En este sentido, la decolonialidad en el estudio de la migración simboliza un campo de oportunidad para ir más allá de los métodos y las metodologías utilizadas de forma tradicional en las investigaciones de corte empírico - analítico en este campo del conocimiento. Por ello, pensar crítica y autocríticamente el contexto, el fenómeno y la complejidad de la migración en el marco de lo transcultural y transnacional significa un espacio de reflexión epistémica destinado a superar los esquemas positivistas, lineales y uniformes que tiene como finalidad hacer una crítica a la visión de objeto de la migración para transitar a la legitimación del sujeto - migrante en la investigación colaborativa y social.

La importancia de plantear una discusión rigurosa sobre la investigación en torno a la temática de los estudios migratorios, tendría que asumir una crítica de la capacidad de reconocer los sujetos, los objetos y los contextos donde se localiza la población de estudio. Esto permite tener un acercamiento de la complejidad y diversidad de elementos que constituyen este fenómeno de investigación. Una oportunidad para reconocer las transformación de un mundo global y contemporáneo, el cual evidencia el tránsito de los migrantes del lugar de origen a un destino, el choque de visones de un lado u otro de la frontera pero en especial los motivos que producen esta serie de movimientos transculturales y trasnacionales.

La visión esquemática impuesta a lo largo de los estudios migratorios sobre la necesidad de caracterizar y definir a la personamigrante, necesariamente obliga a poder reconocer como se inscribe en el discurso moderno - colonial, que responde a los intereses de los organismos internacionales y las políticas institucionales de un régimen político de un país. Así pues, la teoría general sobre la migración contiene en su formato y abordaje teórico - metodológico raíces lineal acordes a los estándares que han caracterizado la población migrante en el ámbito internacional.

De esta forma, se hace complejo abordar en la actualidad la visión de una "persona -migrante" debido a que NO se tiene en cuenta el ser humano como centro en medio de su relación con el ambiente (naturaleza), una forma de reflexionar de adentro para afuera sin caer en los reduccionismo epistémico o las formas de construir conocimiento basado en los criterios de la academia occidental, colonizadora y hegemónica del siglo XX y del presente, el cual de manera estructural se observa en los estudios de la migración. La justificación de reconocer los condicionantes sociales, políticos, históricos, económicos y populares provenientes de la condición del sujeto (migrante) radica en mirar los cambios emocionales, psíquicos, personales y sistémicos producto de la trayectoria en el marco de la migración como fenómeno de investigación social.

La literatura desarrollada por teóricos en los estudios decoloniales considera que este giro - epistemológico desde abajo y con los de abajo en función de construir otras formas de conocer, construir y desarrollar elementos teóricos que sean congruentes con la realidad - social. Así pues, se parte de realizar una crítica - estructural a las formas de conocimiento positivo en el mundo de la investigación en las ciencias sociales. En este caso los resultados de los procesos migratorios han sido asociados a categorías lineales (desigualdad, pobreza, exclusión, negación, violencia), las cuales han sido planteadas por medio de modelos de cuantificación dándole un carácter de objetos - analíticos en el campo de la investigación empírico - analítica.

Por el contrario, analizar desde el paradigma cualitativo, horizontal y crítico teniendo en cuenta la complejidad del fenómeno nos invita a ir más allá de la visión de reconocer al inmigrante como un asunto "irregular" del Estado, un ejemplo de objetivizar la teoría por medio de patrones uniformes del conocimiento, sino dar el paso al legitimarlo como un sujeto - político con un discurso liberador de su propia condición social. 
La propuesta de Santos (2008) de realizar una crítica a las formas modernas del sistema económico - global, consiste en problematizar los elementos pertenecientes a los asuntos propios de la migración y el impacto - profundo que viven las familias inmersas en un contexto de flujo y movimiento constante de un territorio a otro. La lógica de Boaventura de Sousa radica en la necesidad de ver desde las Epistemologías del y desde el Sur como un mecanismo para reconocer los elementos que influyen en este fenómeno social (Díaz, 2015). En el caso de intentar analizar la migración a partir de una perspectiva decolonial significa construir modelos alternativos donde la matriz de dominación sea pensada de manera crítica, pero en particular propositiva de otra realidad por medio de la experiencia del sujeto que migra y en particular la necesidad de rescatar la versión - oral producto de su trayecto migratorio.

El sesgo colonial que evidenciamos en el campo de la migración tiene que ver con las estrategias y herramientas con que se ha teorizado este fenómeno de investigación en el mundo académico - occidental, es decir, los mecanismos que se han utilizado para identificar, simular o reconocer este sujeto en su contexto. Por el contario, emerge la necesidad de hacer una crítica al discurso de objetivizar la teoría, que no tiene la capacidad de reflexionar desde adentro las experiencias locales.

El capitalismo en todas sus expresiones a lo largo de la historia ha generado exclusión. La estructura del neoliberalismo inmersa en las economías de la región, ha sido un modelo de reformar el Estado y el ejercicio de hacer política por medio del valor de uso y no el valor de cambio, el interés sobre el capital y la violación de la dignidad humana son parte del repertorio racista, colonialista y discriminador de esta época. Asimismo, los movimientos poblacionales son de interés en la lógica de la oferta y la demanda con el fin de mercantilizar la vida y explotar los bienes comunales donde habitan grupos sociales en este caso los migrantes (Santos, 2008; Wallerstein, 2005).

Es cierto que la perspectiva de desarrollo ha generado una balanza de desigualdades económicas donde la diversificación de los grupos más pobres aumenta de manera prolongada, dicha situación responde a los intereses e inclemencias del capital y la mercantilización del ser, aquí la situación del migrante no es ajena a este panorama teniendo en cuenta los problemas internos que existen en cada lugar tanto en el caso del Norte al Sur del continente.

En efecto, los ciclos de larga duración tanto en tiempo como en espacio configuran la realidad del migrante, debido a que en su trayecto se conforman un conjunto de estructuras en función de sobrevivir y mantenerse frente a las dificultades que implica ser migrante. A su vez, el ser - migrante se convierte en una manifestación de carácter histórica, política y cultural en términos estructurales, una lógica que nos proporciona elementos para concebir los patrones de dominación del Norte frente al Sur impuesto por el sistema - moderno (colonial) (Díaz, 2015; Sandoval Forero, 2016).

La disputa territorial en torno a un régimen colonial por parte del Norte en su lógica hegemónica en el campo cultural, repercute de forma radical en el diario vivir del sujeto - migrante. Puesto que, representa conocer los códigos políticos que nacen a partir de la experiencia de las comunidades, la importancia de reconocer que la migración también responde a las condiciones de colonialidad y la crisis del sistema capitalismo en la globalización (Sandoval Forero, 2007).

Del mismo modo, el discurso teórico - conceptual de la decolonialidad en el estudio de la migración, toma mayor sentido al momento de contextualizar los datos provenientes de una realidad, es decir, significa dar un paso de la "objetivación" como un discurso eminentemente positivista y reconocer aspectos del sujeto en sus espacios y experiencia migratorios (sentípensante, sujeto - colaborador). Por ello, representa una fractura con las formas modernas - coloniales del conocimiento "científico" impuesto a lo largo de la historia por los centros de investigación, institutos, universidades, gobiernos y entidades internacionales con respecto al campo de la migración en la investigación en las ciencias sociales. 


\section{LA EXPERIENCIA DE LA CULTURA MIGRANTE DEL ESTADO DE MÉXICO}

En el año 2015, el Estado de México entidad federativa donde está ubicado el municipio de Tonatico, registró un total de población de más de 16 millones de habitantes, siendo la entidad más poblada de la República. Es una de las entidades de reciente incorporación al flujo migratorio internacional, documentado e indocumentado (Mora; Sandoval Forero, 2010, p. 51).

El panorama histórico, demográfico y cultural del municipio de Tonatico representa uno de los territorios con mayores índices de flujo migratorio, un fenómeno que nos permite conocer a partir de una experiencia local factores, elementos, procesos y problemáticas que trae consigo la migración en sus distintas vertientes. La constante interacción de comunidades de Estados Unidos y México en esta región es símbolo de integración, solidaridad, reconocimiento y participación sobre el sentido de ser migrante y tener que cargar con esa tradición en el municipio (Calderón; Martínez, 2002). Es una población que con el transcurrir de los años pasó de vivir una diversidad excluyente a una diversidad social y cultural de la inclusión, de la convivencia pacífica, de la no violencia y del respeto intercultural.

El municipio de Tonatico celebra "el día del migrante ausente", una fiesta de gran importancia por el carácter simbólico y la interacción social tan fuerte que se genera sobre este acontecimiento, este suceso generalmente es festejado la segunda semana de enero y concluye en la primera de febrero, en ese espacio de tiempo muchos de los migrantes vienen de Estados Unidos a visitar, compartir e interactuar con sus familiares mexicanos, volver a recorrer sus localidades y revivir experiencias provenientes de su pasado - vivo, sin dejar a un lado la celebración de la virgen de la Candelaria, donde asisten al ritual de peregrinación que inicia en la entrada del pueblo y termina hasta la catedral principal del mismo pueblo (Sandoval Forero; García, 2010).

Al respecto de esta festividad, se generan una serie de aspectos fundamentales que nos permite conocer a profundidad eventos y sucesos que contribuyen a la identidad, la multiculturalidad y el fenómeno transnacional y transcultural presente en Tonatico. Los tonatiquenses que por diversas razones han emigrado a los Estados Unidos de Norteamérica, ya sea de manera documentada o indocumentada, se localizan principalmente en Chicago, Waukegan, Milwaukee y California, en estas geografías participan en actividades económicas como la agricultura, los servicios (limpieza, restaurante, artesanías, hoteles y en menor medida el pequeño comercio).

Al mismo tiempo,

Los tonatiquenses reciben además de las remesas económicas, transferencias culturales que de manera general se definen como remesas sociales y culturales. Pero también en sentido contrario, en la sociedad de acogida de los inmigrantes, llegan, exhiben y reproducen remesas culturales mexicanas, que contribuyen al vivir de los inmigrantes y al establecimiento de relaciones interculturales entre mexicanos y norteamericanos. La multiplicidad de relaciones y sus concreciones en los clubes de migrantes, son elocuentes referentes de la utilidad y beneficios de las Nuevas Tecnologías de Información y comunicación (NTIC), particularmente internet, que simboliza la apropiación tecnológica de estos actores sociales transnacionales (Sandoval Forero, 2013, p. 2).

Uno de los lazos transculturales y transnacionales de gran vitalidad de la población de este municipio es el intercambio de expresiones, lenguajes, idiomas, remesas y experiencias producto del origen y el regreso del municipio, en este proceso de comunicación aparecen el envío de remesas económicas, la participación en las fiestas del pueblo, la recreación de momentos solidarios y la necesidad de reconocer las diferencia y autonomía que existe en ambas culturas. 
Sumado a esto el

envió de remesas económicas y culturales, participan en las fiestas del pueblo con aportaciones de dinero, con castillos de fuegos pirotécnicos, muchos van y vienen a las festividades religiosas, asisten a la feria de Tonatico, organizan encuentros con las autoridades del ayuntamiento, juegan partidos de fútbol, montan pequeños negocios como misceláneas, cibercafés y posadas familiares. Son significativas las remesas culturales en los dos sentidos geográficos: las que llegan de Estados Unidos y las que se llevan de Tonatico (México), es decir que hay interacción cultural de la sociedad expulsora con la sociedad receptora, y en ello juega un papel importante los hijos de los tonatiquenses nacidos en USA. La diversidad de redes solidarias en este complejo migratorio se hace presente a través de redes familiares, sociales, culturales, de paso de migrantes, de recepción en el país de arribo, de las remesas, de participación en las fiestas patronales, y de los clubes de migrantes (Sandoval Forero, 2013, p. 5).

La multiplicidad de acciones, sentimientos y recuerdos que se concentran en las fiestas de Tonatico nos muestra el flujo de relaciones sociales, políticas y económicas de los migrantes en sus respectivas actividades: los fuegos pirotécnicos, las festividades religiosas, los eventos de la feria y el encuentro con las autoridades del ayuntamiento permite una comunicación entre los de arriba con los de abajo, al mismo tiempo la integración a través del futbol hacen parte del conjunto de prácticas culturales que se desarrolla en el municipio.

En ese sentido, la representación simbólica es resultado del ritual e hibridez cultural debido a la migración en Tonatico, por este lado, logramos presenciar como las fiestas de la independencia de México se vive simultáneamente con la población migrante en los Estados Unidos donde la comunidad "Tonaca" genera un concurso para escoger una Reina de EUA haciendo un recorrido principalmente en Waukegan que es el lugar donde más residen los migrante tonatiquenses.

La fuerte presencia de migrantes de Tonatico es una muestra de la dinámica de comunicación existente en ambos territorios por parte de familiares, amigos, parejas, colegas entre otros. Estos actores facilitan la interacción en materia económica, política y cultural donde lo transcultural y transnacional está cada vez más vigente en esta comunidad. Asimismo, la creación de clubes, reuniones y proyectos que vinculan a los migrantes son de utilidad y beneficio para el uso de las NTIC en esta región.

De esta forma, lo que sucede en Tonatico contribuye a que:

se examine la forma en que estas redes funcionan como vínculos para gestionar la fragmentación del espacio social de los migrantes y la hibridación de una comunidad imaginada y virtual. También se considera el grado de usabilidad y apropiación de los medios al alcance de los usuarios, con el criterio de la penetración de la comunidad y la participación de los distintos actores desde los diferentes lugares que integran el circuito migrante (Mora; Sandoval Forero, 2010, p. 62).

Los migrantes son quizás uno de los actores sociales más expuesto a la violencia estatal y la crisis del capital producto de las relaciones de mercantilización que impone la ideología neoliberal. La cuestión de este fenómeno se articula con la complejidad, efervescencia y necesidad que trae consigo el migrante en medio de su trayecto por lograr su objetivo, por eso, la construcción de lo transcultural y transnacional tiene que ver con las transformación del tiempo, el espacio y los discurso que se van desarrollado en lo concerniente a los intereses de las comunidades tanto de Estados Unidos como lo que sucede en México, es decir, son una relación reflexiva y de mutuo aprendizaje.

La hibridación transcultural y transnacional que experimentan la población de Tonatico expresa las categorías espaciales y temporales para reconocer las prácticas, discursos y formas de interacción entre ambas regiones. Lo cual contribuye a reconocer las actividades fundamentales que fortalecen un tipo de identidad - comunitaria sobre y para los integrantes de 
las familias migrantes. Por ello, los elementos de arquitectura, las fiestas y la alegoría por el recuentro en su ser contiene los elementos del giro decolonial, debido a que es una integración de grupos subalternos, oprimidos y con una razón de ser desde abajo (Díaz, 2016; Sandoval Forero, 2016).

Por esta razón, la comunidad de Tonatico ofrece elementos fundamentales para analizar el tipo de organización, la cohesión social y el discurso de legitimidad frente al ser -migrante como un sujeto de derechos individuales y colectivos. Una lógica que expone las necesidades y demandas del territorio mexicano más allá de la frontera y viceversa, significa un momento histórico para apropiarse de las prácticas identitarias que son congruentes con la organización de la población, dado que

así, la imagen que se tiene de la comunidad transnacional que abarca la comunidad de origen y las comunidades de destino, se transforma de proceso social de identidades a participación e involucramiento, y se produce por esa vía una transmutación hacía la membresía activa de los encuentra una importante fase de organización y cohesión en el territorio mexicano, a través de la organización comunitaria y las formas de interacción cotidiana; en Estados Unidos, mediante los clubes de migrantes que representan una célula de organización de importante presencia "migrantes" (Moctezuma, 2008, p. 57 citado por Mora; Sandoval Forero, 2010, p. 90).

También el significado que adquieren las remesas culturales en los espacios geográficos, puesto que llegan de Estados Unidos y las que se llevan de Tonatico es una realidad - empírica, este panorama de interacción cultural entre la sociedad receptora y la expulsora muestra una vez más el plano transnacional donde aparecen estos episodios como una muestra del papel que juega el migrante en la aparición de otros elementos que constituyen el discurso de los estudios de migración.

Así el sentido de apropiación por el territorio y la necesidad de fortalecer los rasgos culturales entre dos naciones. Tal como lo presenciamos "Nuestra segunda bandera es la de Estados Unidos porque en ese país vivimos y viven nuestros hijos. No olvidamos nuestra bandera, y también la tenemos en Illinois" (Mora; Sandoval Forero, 2010, p. 57). La importancia de este encuentro para los habitantes Tonatiquenses consiste en establecer rutas de pensamiento donde confluya el respeto, la abnegación y el orgullo de ambas partes (origen y acogida). Así mismo, los migrantes esgrimen su vivencia en la cuestión de inserción laboral, la vida social, la condición de indocumentado y la cooperación que se genera entre la comunidad frente a la necesidad de no perder la identidad - cultural.

Por ende, el sujeto migrante evidencia un fenómeno de desterritorialización cultural y simbólica de su lugar de origen hasta su nuevo reto al ingresar a un contexto - desconocido. La aparición de nuevos espacios, momentos y tiempos son la muestra real de los choques culturales a partir de su contacto con la realidad - social. La construcción social estructurada de este fenómeno cultural como es la migración, nos invita a reconocer la concepción de lo simbólico en los problemas y la importancia del sujeto como un ser social y político más allá de las circunstancias que atraviesan su contexto.

Las formas simbólicas son construcciones significativas donde lo transcultural y lo transnacional entran en juego debido al margen de interrelación entre los migrantes y el nuevo espacio de interacción cultural del individuo con su contexto social. En esta línea argumentativa la producción de prácticas y la apropiación de su condición como ser en comunidad, le permite poner de manifiesto el sentido significativo de las estructuras que influyen en la migración estas que son funcionales al sistema mundo-moderno.

En este mismo sentido,

la complejidad de la migración tonatiquense manifiesta la consolidación de vínculos familiares y sociales de relaciones MéxicoEstados Unidos, en todos los rangos de edad y con generaciones de hijos de tonatiquenses nacidos y criados en el país vecino, lo que genera consecuencias, allá y acá, en todos los aspectos de la vida cotidiana y política (Sandoval Forero, 2013, p. 7). 
Esta compleja realidad de las comunidades de mexicanos en Estados Unidos y sus relaciones interculturales pacíficas con las comunidades en México, han sido tejidas a través de muchos años de interacción, donde la comunicación constante ha sido uno de los determinantes para el establecimiento de relaciones de reconocimiento social y cultural en los dos lados de la frontera. Con el diálogo y la comunicación permanentes han construido puentes de ayuda, solidaridad, respeto y convivencia armónica de culturas tan disímiles como la de Estados Unidos y México.

\section{A MODO DE CONCLUSIÓN}

El imaginario colectivo generado en la migración tiene su asidero en el conjunto de representaciones simbólicas donde los migrantes expresan sus múltiples comunicaciones, acciones y formas de concebir su experiencia a partir del contexto en el cual se desarrollan como sujeto en uso de sus derechos y empoderamiento de su condición como ciudadanos - migrantes.

La construcción simbólica que se puede rescatar de la migración nos permite ir más allá de los debates clásicos y lograr proponer otras epistemologías donde la migración tome mayor sentido en su apuesta por contextualizar la teoría. Lo que implica, establecer rutas, herramientas y mecanismos donde la descolonización sea la bandera de crítica - política en el marco de las estructuras del sistema mundo - capitalista.

La migración es el resultado de un fenómeno que acompaña el desarrollo de la historia de la humanidad. En la actualidad, se presenta como realidad trasnacional y transcultural en el marco de una geopolítica del poder en la región, por ello, las migraciones se constituyen como un patrón de referencia que permite situarnos en dos planos: el primero, el desarrollo personal, económico, científico y tecnológico que le pueda ofrecer el país acogedor al sujeto migrante, y el segundo, tiene que ver la generación de violencias directas, indirectas y estructurales que sufre este tipo de población producto de las transformaciones que implica el reconocimiento de la ciudadanía en la sociedad receptora.

En efecto, los vínculos que se generan en el proceso de migración entre México y Estados Unidos, pone como actor fundamental a los migrantes en su apuesta por reconocer la transterritorialidad de relaciones que se ven presentes en la familiaridad, las redes de migración, la conexión por medios virtuales y la constitución de una cultura migratoria.

El fenómeno de la migración desde una perspectiva crítica se relaciona de manera dimensional con aspectos económicos, políticos, sociales, culturales, laborales y particularmente con la visión de los derechos humanos en un contexto globalizado. Así pues, el carácter de lo transnacional y transcultural son elementos funcionales en el reconocimiento de la complejidad que existe en el estudio de la migración en el marco de los estudios decoloniales.

Igualmente, la crítica a los instrumentos, herramientas y mecanismos internacionales como estratagemas del sistema capitalista, representa un conjunto de espacios para la crítica y la generación de formas alternativas de conocimiento donde el sujeto - migrante tenga la capacidad reflexiva y liberadora de ser partícipe de su propia realidad - social. Lo que se convierte en una oportunidad por reconocer los fenómenos de esta época y la importancia de ir más allá de la visión normativa, procesal y positiva del conocimiento en el estudio de la migración.

En últimas, la migración transnacional y transcultural en el Estado de México y específicamente en el municipio de Tonatico es un ejemplo profundo para tener en cuenta experiencias donde la decolonialidad sea la base teórica, el puente y el canal para establecer un proceso liberador, crítico y autocrítico por generar conocimiento desde abajo y con los de abajo en función de construir epistemologías anti-coloniales y en lo posible congruente con el contexto local del sujeto, las familias 
y los actores vinculados al tránsito de la migración y el reconocimiento de las particularidades existentes en el campo de la migración de población Mexicana en los Estados Unidos.

Sin duda que la comunicación ha sido un potencializador de la convivencia cultural pacífica, no solo en las relaciones interculturales de la población de Estados Unidos y México, sino también de las relaciones entre la misma comunidad de migrantes en ambos lados de la frontera.

\section{REFERENCIAS}

BRYCESON, Deborah; VUORELA, Ulla. The transnational family; new european frontiers and global networks. Oxford: Oxford University Press, 2002.

CALDERÓN, Leticia; MARTíNEZ, Jesús. La dimensión política de la migración mexicana. Ciudad de México: Instituto Mora, 2002.

CASTORIADIS, Cornelius. La institución imaginaria de la sociedad. Buenos Aires: Tusquet, 1993.

CASTRO-GÓMEZ, Santiago; GROSFOGUEL, Ramón. El giro decolonial: reflexiones para una diversidad epistémica más allá del capitalismo global. Bogotá: Siglo del Hombre, 2007.

DÍAZ, Sergio Prieto. Migración indocumentada y colonialidad: una aproximación tentativa. Clivajes, Ciudad de México, v. 4, n. 90, p. 90-105, 2015.

La migración indocumentada desde una otra perspectiva: colonialidad, sujeto subalterno, y mapeos migrantes. Iberóforum, Ciudad de Mexico, v. 11, n. 22, p. 31-63, 2016.

GALTUNG, Johan. Paz por medios pacíficos: paz y conflicto. Bilbao: Bakeaz: Gernika Gogoratuz, 2003.

GROSFOGUEL, Ramón. Descolonizando los universalismos occidentales: pluri-versalismo transmoderno decolonial de Aimé Cesaire a los zapatistas. In: CASTRO-GÓMEZ, Santiago; GROSFOGUEL, Ramón (Eds.). El giro decolonial: reflexiones para una diversidad epistémica más allá del capitalismo global. Bogotá: Siglo del Hombre: lesco, 2007. p. 63-77.

HONNETH, Axel. La lucha por el reconocimiento. Barcelona: Ediciones Crítica, 1997.

MORA, Carlos; SANDOVAL FORERO, Eduardo Andrés. El caso de estudio: Tonatico, estado de México. In: SANDOVAL FORERO, Eduardo Andrés; GARCÍA, Ernesto Guerra. Migrantes e indígenas: acceso a la información en comunidades virtuales interculturales. Toluca: Universidad Autónoma del Estado de México, 2010. p. 51-131.

SANDOVAL FORERO, Eduardo Andrés. Migración e identidad: experiencias del exilio. Toluca: Universidad Autónoma del Estado de México, 1994.

Los migrantes indocumentados y los derechos humanos. Eumed.net, Málaga, 12 nov. 2007. Disponível em: <https:// goo.gl/V83kc5>. Acesso em: 4 jun. 2018. 
Ciudadanía universal, derechos políticos y paz en la migración. In: MARTíNEZ GUZMÁN, Vicent; SANDOVAL FORERO, Eduardo Andrés. Migraciones, conflicto y cultura de paz. Toluca: Bonobos, 2009. p. 19-45.

Movimiento asociativo de migrantes, transculturalidad y comunicación para la paz. In: ARÉVALO SALINAS, Alex Iván. Migraciones y cultura de paz. educando y comunicando solidaridad. Madrid: Dykinson, 2012. p. 233-252.

Remesas e imaginarios colectivos en Tonatico, estado de México. Cebem, La Paz, 27 jul. 2013. Disponível em: <https:// goo.gl/0oP5KG>. Acesso em: 4 jun. 2018.

. Conflictos y empoderamiento pacífico en la migración indocumentada. E-marc, Buenos Aires, 11 maio 2015. Disponível em: https://goo.gl/2Fqh91. Acesso em: 5 jun. 2018.

Educación para la paz integral: memoria, interculturalidad y decolonialidad. Bogotá: ARFO, 2016.

SANDOVAL FORERO, Eduardo Andrés; GARCÍA, Ernesto Guerra. Migrantes e indígenas. acceso a la información en comunidades virtuales interculturales. Toluca: Universidad Autónoma del Estado de México, 2010.

SANTOS, Boaventura de Sousa. Pensar el Estado y la sociedad: desafíos actuales. Buenos Aires: Waldhuter, 2008.

WALLERSTEIN, Immanuel. Análisis del sistema-mundo: una introducción. Ciudad de Mexico: Siglo XXI, 2005.

ZAPATA-BARRERO, Ricard. Multiculturalidad e inmigración. Madrid: Sistensis Editorial, 2004.

Artículo recibido el 08.04.2018 y aprobado el 22.05.2018. 